\title{
Evaluate of the Effects of Drilling with Varying Spindle Speed Using Different Thickness of GFRP on the Damage Factor
}

\author{
Woo Tze Keong ${ }^{1, a}$, Faiz Ahmad ${ }^{2}$, Safian Sharif ${ }^{3}$ and Mohd Azuwan Moinser ${ }^{4}$ \\ ${ }^{1,2,4}$ Universiti Teknologi Petronas, Malaysia \\ ${ }^{3}$ Universiti Teknologi Malaysia, Malaysia
}

\begin{abstract}
Composite have been widely used in industries which such as aircraft structural components, electric and electronics components, aerospace, and oil and gas fields due to their superior mechanical properties. Among machining process, drilling can be considered as one of the most important process in final machining of composite. In this research, vacuum assisted resin infusion method is use in fabricating the glass fiber reinforcement polymer samples, where different thickness of GFRP were used in the drilling process with different spindle speed. The results show that the temperature influences the damage factor of the drilling. Higher spindle speed will generate higher temperature that softens the matrix thus generating lower damage factor. The suitable drill bit temperature is between $150-200^{\circ} \mathrm{C}$
\end{abstract}

\section{Introduction}

During the past decades, the field of composite materials has developed tremendously in areas such as aircraft, spacecraft and even in oil and gas field. Due to its light weight, high strength, and resistance to corrosion, fiber reinforced composites are being used to replace steel for certain parts in the industries [1]. Composite can be characterized as a material consist of two or more different materials where the properties of the resultant materials will benefits from these combined materials[2]. Although most composite parts are fabricated to near net shape, some finally machining processes are still need especially drilling holes for fasteners.

Joining of smaller composite laminates parts into bigger structure is always the case due to limitation of transportation and fabrication. However, effects of drilling generated heat on the resin infusion fabrication GFRP and how it affects the mechanical properties of GFRE have not yet been fully examined. The lack of available data of these materials makes the findings of the study of potential importance towards understanding the microstructure and behavior of the glass fiber laminates during the drilling process.

\footnotetext{
${ }^{a}$ Corresponding author: kenz78@gmail.com
} 


\section{Fabrications of Samples}

Composite materials has been widely use since the ancient Chinese, Israelites and Egyptians. The use of straw mixed with clay in their building structure has made them the very first civilisation that utilise the advantages of composite [3]. In aerospace industry, GFRP are used mainly in cabin design such as fairings, doors, seats, and passenger compartment rather than using metal alloys in order to reduction weight and cost[4].

\subsection{Glass Fiber}

Fiber consists of thousands of filaments with diameters between 5 to 15 micrometers, where they are weave using textile technology [5]. There are various types of reinforcements, such as continuous, woven or chopped fiber which can increase the mechanical properties of the composites. In this research, E-glass woven fiber (table 1) was used as reinforcement material to produce fiber composites. The fiber woven glass fabric is a bidirectional fabric made by non-weave roving in plain weave pattern.

Table 1. Technical specification of the Woven Glass Fiber used

\begin{tabular}{|l|l|}
\hline name & CWR400 \\
\hline Yarn type & E-glass \\
\hline applications & hand and machine production \\
\hline weight & $380^{+} .40 \mathrm{~g} / \mathrm{m}^{2}$ \\
\hline thickness & $0.400 \pm 0.040 \mathrm{~mm}$ \\
\hline
\end{tabular}

\subsection{Epoxy}

Epoxy is one of the thermosetting resins which are going to be used in this research to fabricate fiber composites. The liquid state at room temperature made it a very versatile element to be used as matrix. With the usage of different volume of hardener, we can control the hardening of the matrix. Resin is a good resistance to most chemicals, good resistance to creep and fatigue, high strength and good electrical properties [6].

\subsection{Vacuum Assisted Resin Infusion Fabrication}

Vacuum pressure is used to force resin into the laminate. The glass fibers were laid dry on the mould while a vacuumed space condition was achieved before resin is channelled into the laminate. Instead of manually wetting the reinforcements using hand lay-up, this technique used a vacuum bag to extract the excess resin out from the laminate. Vacuum method has more advantage in term of superiority of the final GFRP, by archiving better fiber-to-resin ratio [8,9]. The pressure used in the fabrication process was set to $90 \mathrm{bar}$, while it was cured in the oven with tempperature of $90^{\circ} \mathrm{C}$ for 2 hours.

\section{Characterization of the samples}

Glass fibers possess very high specific properties. With its high stiffness and strength to weight ratio, makes them a popular option especially as the reinforcing elements in the composite materials [10]. It is important to control the ration between the matrix and fiber in order to archive the desire properties [11].

The mechanical properties of fiber reinforced composites were very dependent on content of the reinforcing fiber, thus high fiber volume fraction is preferred [12]. To fabricate the composites, assisted resin infusion method were used. Resin infusion is easier to operate as to compare to hand 
layout, which greatly reducing labour costs [13]. The manufactured products have very low porosity and surface finish is good compared to the other techniques such as hand lay-up and spray-up molding. According to Atas et al., samples formed by infusion process are approximately $54 \%$ higher in flexural strength than that of hand lay-up [7]. Before continue to the drilling experiment stage, the samples will undergo tests to determine its properties. The tests done on the sample are as below

\subsection{Burn off Test}

In order to determine properties of a composite material, relative proportions of the matrix and reinforcing materials is importantly be referred from fiber volume fraction, $V_{f}$ which is more significant and used significantly in theoretical analysis of composite materials [12]. Rule of mixtures used to define $V_{f}$ where it is the method to approximate estimation of the properties from assumption that volume weighed average of the phase's properties.

The volume fraction resulted from the fabrication was between $\left(0.58<\mathrm{V}_{\mathrm{f}}<0.62\right)$. It is categorize under intermediate fiber volume fraction and exhibit brittle failure with fiber pullout [12]. These ranges are applicable if the void content in the composite is negligible. The test was performed adhering to ASTM D 2584 where the test uses ignition loss of the resin to determine the volume of the fiber left after the resin has been burn off.

\section{Experiment}

As this is a continuous of the previous research [14], the set up of the experiment was kept constant so that the results of the experiment are consistent. The drilling of GFRE was done on Mazak Variaxis 630-5X CNC machine due to its capability to drill at high speed. A $6 \mathrm{~mm}$ diameter High Speed Steel drill bit was used throughout the experiment. The specimen size for the drilling process was $250 \times 25 \mathrm{~mm}$.

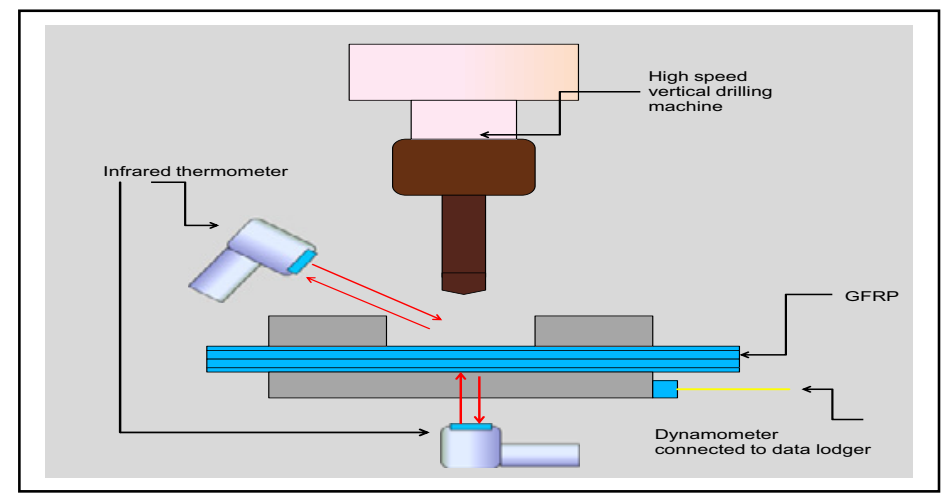

Figure 1. Experiment set up

The design of the experimental set up is based on the predominant factors selected through literature review of previous researches [14] in order to further investigate the temperature effects on the damage factor. The Feedrate of the drilling was set to be constant at $300 \mathrm{~mm} / \mathrm{min}$ where the varying predominant factors selected were:

Table 2. Predominant manipulated parameters for this experiment

\begin{tabular}{|c|c|c|c|c|}
\hline Spindle Speed & $6000 \mathrm{RPM}$ & $9000 \mathrm{RPM}$ & $12000 \mathrm{RPM}$ & $15000 \mathrm{RPM}$ \\
\hline Thickness & $3 \mathrm{~mm}$ & $5 \mathrm{~mm}$ & $7 \mathrm{~mm}$ & $9 \mathrm{~mm}$ \\
\hline
\end{tabular}


The drilling was performed using a high speed drilling machine (Figure 1). GFRP is mounted on the work table with the infrared thermometer fix at the entrance and exiting point of the drill. Delamination will be measured using a microscope and 3D non contact inspection machine. Experiment is carried out without coolant (dry drilling). 100 holes were drilled at each different thickness of the GFRP. The drill bit was left to cool down after each 10 holes interval. The temperatures generated were recorded.

\section{Results and Discussion}

\subsection{Burn off test results}

Table 2 shows the results for the resin burn off test from 4 different thicknesses of GFRP samples fabricated using the vacuum resin infusion method. It can be observed that the vacuum resin infusion method used to fabricate the GFRP was consistently producing samples of within the range of 55- 65\% fiber volume fraction. It is very crucial to produce samples with constant fiber volume fraction, as different fraction will influence the mechanical properties of the GFRP.

Table 3. Fiber volume fraction of 4 different thickness of GFRP

\begin{tabular}{|c|c|c|c|c|c|c|c|}
\hline sample & $\begin{array}{c}\text { GFRP mass in } \\
\text { air } \mathbf{( g )}\end{array}$ & $\begin{array}{c}\text { GFRP mass in } \\
\text { water }(\mathbf{g})\end{array}$ & $\begin{array}{c}\text { GFRP density } \\
\left(\mathbf{g} / \mathbf{c m}^{\mathbf{3}}\right)\end{array}$ & $\mathbf{W}_{\mathbf{f}}$ & $\mathbf{W}_{\mathbf{m}}$ & $\mathbf{V}_{\mathbf{f}}$ & \multirow{2}{*}{ Average } \\
\hline S1-14L & 6.051 & 2.805 & 1.803 & 4.158 & 1.893 & 58.24 & \multirow{2}{*}{60.02} \\
\hline S2-14L & 5.841 & 2.705 & 1.855 & 4.12 & 1.721 & 59.64 & \\
\hline S3-14L & 6.53 & 3.026 & 1.892 & 4.773 & 1.757 & 62.18 & \\
\hline S1-11L & 6.076 & 2.707 & 1.7984 & 4.239 & 1.824 & 59.67 & \multirow{2}{*}{59.84} \\
\hline S2-11L & 6.533 & 3.034 & 1.8607 & 4.758 & 1.775 & 60.1 & \\
\hline S3-11L & 7.266 & 3.267 & 1.8188 & 5.108 & 2.158 & 59.84 & \multirow{2}{*}{57.35} \\
\hline S1-8L & 1.561 & 0.664 & 1.734 & 1.065 & 0.496 & 58.65 & \\
\hline S2-8L & 1.204 & 0.551 & 1.8376 & 0.824 & 0.38 & 57.5 & \\
\hline S3-8L & 1.228 & 0.552 & 1.80794 & 0.835 & 0.393 & 57.35 & \multirow{2}{*}{57.76} \\
\hline S1-5L & 1.271 & 0.561 & 1.7845 & 0.865 & 0.406 & 57.74 & \\
\hline S2-5L & 1.09 & 0.479 & 1.7773 & 0.742 & 0.348 & 57.9 & \\
\hline S3-5L & 1.031 & 0.452 & 1.7742 & 0.698 & 0.331 & 57.64 & \\
\cline { 1 - 4 }
\end{tabular}

\subsection{Effect of Temperature generated through varying Spindle Speed on Damage Factor with different thickness of GFRP}

In this experiment, different thickness of GFRP were used $(3 \mathrm{~mm}, 5 \mathrm{~mm}, 7 \mathrm{~mm}, 9 \mathrm{~mm})$. Each thickness will cut into strips of small samples where each samples were drilled 10 holes, and the drill bit will be left cooled before proceed to subsequent 10 holes.

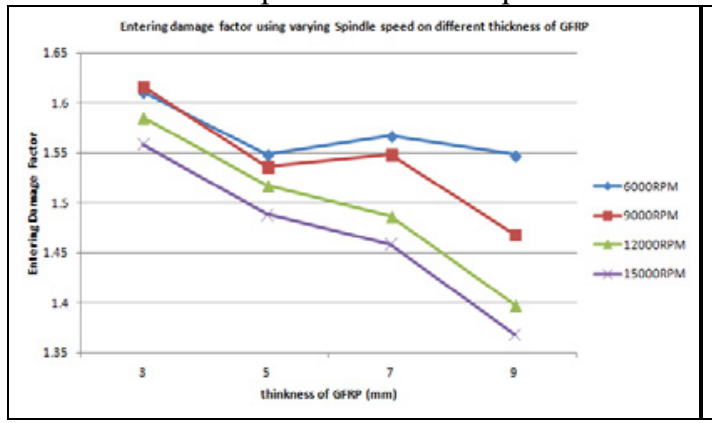

Figure 2. Entering damage factor for 4 spindle speed on 4 different thickness of GFRP

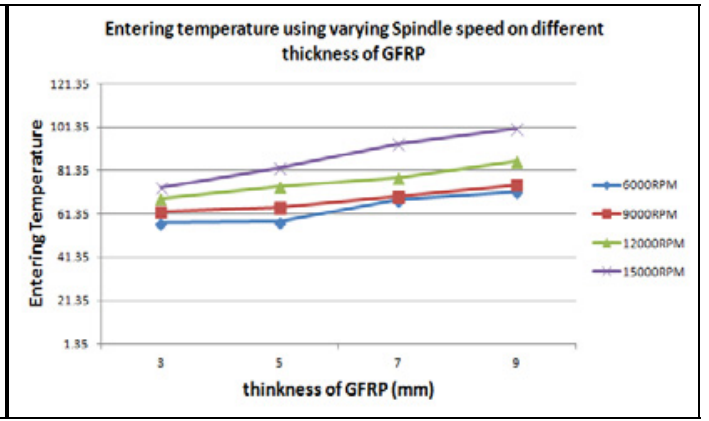

Figure 3. Entering temperature of the drill bit under 4 different spindle speed on 4 different thickness 
From the experiment, (figure 2) the results showed than the damage factor of $3 \mathrm{~mm}$ thickness of GFRP remained high throughout the different spindle speed, but lowest damage fator can be archieved using higher spindle speed. As thicker GFRP was drilled, the damage factor decreased gradually on thinner GFRP, but a drastic decreased in damage factor when it comes to thicker GFRP. This was because the interlaminar force of thicker GFRP was stronger compare to thinner GFRP where fewer layer of fiber clothes was used. The stiffness increases for the thicker GFRP also influence the damage factor, this prevented the GFRP from bending during the drillling process thus decreased the damage factor. The temperature generated throughout the drilling process can be observed in graph figure 3 . It showed that the temperature of the drill bit increased while the spindle speed increased. Damage factor can be seen decreased when the temperature of the drill bit increased, this was due to the temperature aiding in softened the epoxy thus eases the drilling process while generating lower damage factor.

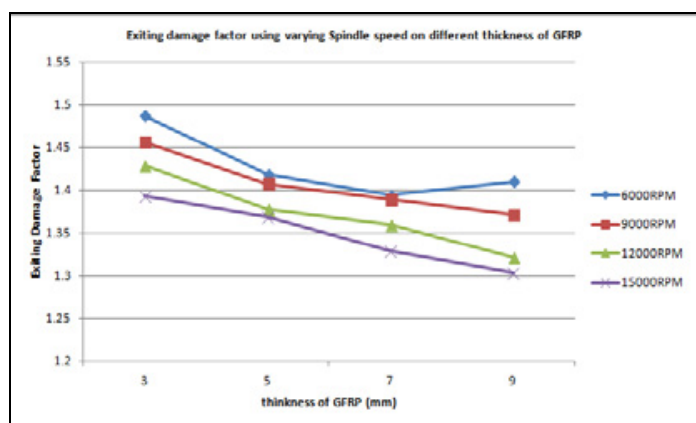

Figure 4. Exiting damage factor for 4 spindle speed on 4 different thickness of GFRP

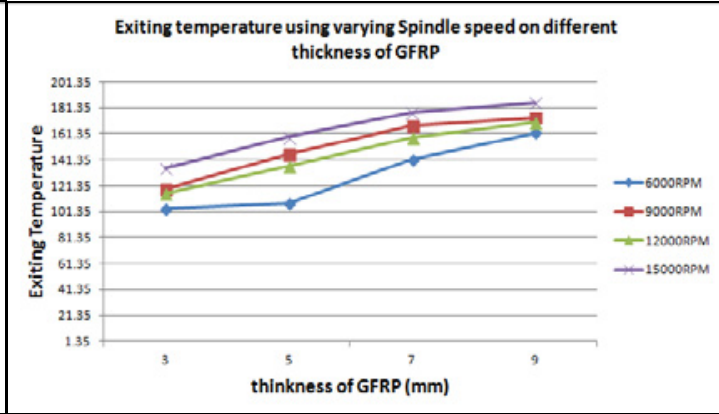

Figure 5. Exiting temperature of the drill bit under 4 different spindle speed on 4 different thicknesses

Figure 4 and figure 5 showed than the higher the spindle speed at lower feedrate generated lower damage factor for all thickness of GFRP. But lower damage factor was obtained using thicker GFRP. The temperature of the exiting drill bit also increased drastically with higher spindle speed.

\section{Conclusions}

From the results, vacuum resin infusion method was suitable for producing GFRP with 55- 66\% fiber volume fraction which complies with the industrial standard. Higher spindle speed generates higher temperature; this drastically decreases the damage factor. When drill bit temperature reached $150-200^{\circ} \mathrm{C}$, it generates lower damage factor, due to softening of the matrix which helps the cutting process. Thickness of the GFRP samples also influences the temperature generated and the damage factor. Thicker GFRP will have lower damage factor compares to thinner GFRP due to its stiffness in withstanding pulling and pushing force generated during the drilling. When drilling thicker GFRP, higher temperature is recorded while generating lower damage factor.

\section{References}

1. Mohan, N. S., Ramachandra, A., \& Kulkarni, S. M., Composite Structures , 71 (3-4), 407413(2005)

2. Budinski, K. G., \& Budinski, M. K., Engineering Materials: Properties and Selection (9th Edition). Prentice Hall PTR, 2010.

3. Pihtili, H., International Journal of Machine Tools \& Manufacture , 937-946. (2011).

4. Gay, D., Hoa, S. V., \& Tsai, T. S., Composite Materials Design and Applications. Florida: CRC Press LLC. (2003). 
5. Jweeg, M. J., Hammood, A. S., \& Al-Waily, International Journal of Mechanical \& Mechatronics Engineering, 62. (2012).

6. Sims, G. D., and Broughton, W. R., Polymer Matrix Composites. (2001).

7. Liu, D. F., Tang, Y. J., \& Cong, W. L., Composite Structures. 1265-1279. (2012).

8. Davim, J. P., and Pedro, R., Composite Structure , 481-487. (2003).

9. Sardinas, R. Q., Reis, P., \& Davim, J. P., Compos Sci Technol. 3083-3088. ( 2006).

10. Khashaba, U. A., Composites structures. 313-327. (2004).

11. Ishikawa, T., Adv Polym Sci, 109-144. (2005).

12. Hull, D., \& Clyne, T. W., New York: University press, Cambridge. (2003).

13. Modi, D., Correia, N., Johnson, M., Long, A., Rudd, C., and Robitaille, F., Composite Part A: Applied Science Manufacturing. 1271-1287. (2007).

14. Woo Tze Keong, Faiz Ahmad, Safian Sharif and Mohd Azuwan Moinser., Key Engineering Materials. 594-595, pg 661-665 (2013) 